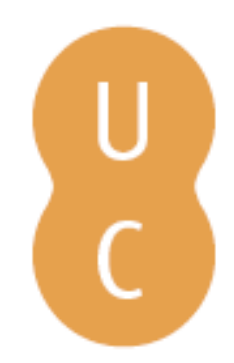

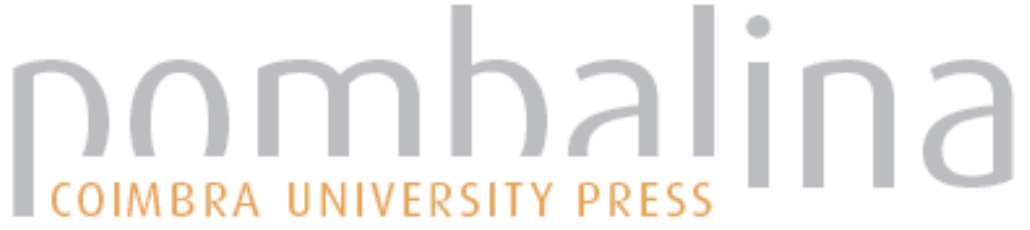

\section{Personagens de Antígona, Helena e de Medeia na trilogia de Hélia Correia}

\author{
Autor(es): $\quad$ Manojlovich, Tatjana \\ Publicado por: Imprensa da Universidade de Coimbra \\ URL \\ persistente: URI:http://hdl.handle.net/10316.2/32322 \\ DOI: $\quad$ DOI:http://dx.doi.org/10.14195/978-989-26-0391-9_10 \\ Accessed : $\quad$ 26-Apr-2023 13:59:40
}

A navegação consulta e descarregamento dos títulos inseridos nas Bibliotecas Digitais UC Digitalis, UC Pombalina e UC Impactum, pressupõem a aceitação plena e sem reservas dos Termos e Condições de Uso destas Bibliotecas Digitais, disponíveis em https://digitalis.uc.pt/pt-pt/termos.

Conforme exposto nos referidos Termos e Condições de Uso, o descarregamento de títulos de acesso restrito requer uma licença válida de autorização devendo o utilizador aceder ao(s) documento(s) a partir de um endereço de IP da instituição detentora da supramencionada licença.

Ao utilizador é apenas permitido o descarregamento para uso pessoal, pelo que o emprego do(s) título(s) descarregado(s) para outro fim, designadamente comercial, carece de autorização do respetivo autor ou editor da obra.

Na medida em que todas as obras da UC Digitalis se encontram protegidas pelo Código do Direito de Autor e Direitos Conexos e demais legislação aplicável, toda a cópia, parcial ou total, deste documento, nos casos em que é legalmente admitida, deverá conter ou fazer-se acompanhar por este aviso.

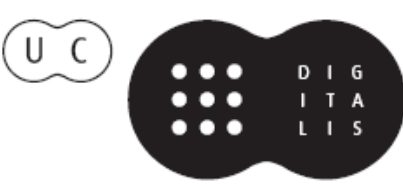


Maria de Fátima Sousa e Silva

Coordenação

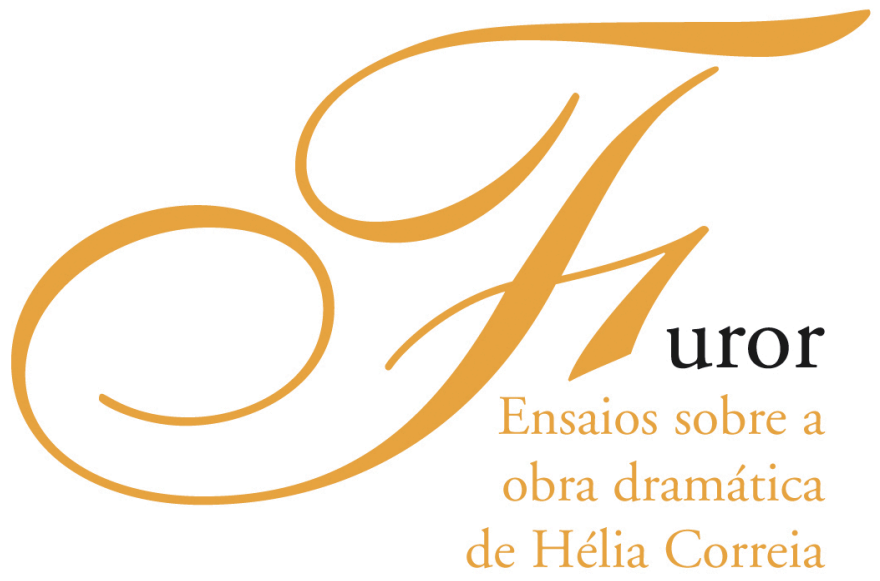

- COIMBra 2006 
COORDENAÇÃO EDITORIAL

Imprensa da Universidade de Coimbra

URL: http//www.imp.uc.pt

\author{
CONCEPÇÃO GRÁFICA \\ António Barros \\ PAGINAÇÃO \\ Inova \\ EXECUÇÃO GRÁFICA \\ Inova - Artes Gráficas \\ Porto
}

ISBN

972-8704-94-1

DEPÓSITO LEGAL

247166/06

C OUTUBRO, 2006, IMPRENSA DA UNIVERSIDADE DE COIMBRA

OBRA PUBLICADA COM O APOIO DE:

Centro de Estudos Clássicos e Humanísticos

FCT Fundação para a Ciência e a Tecnologia

MINISTÉRIO DA CIÊNCIA, TECNOLOGIA E ENSINO SUPERIOR Portugal 
Maria de Fátima Sousa e Silva

Coordenação

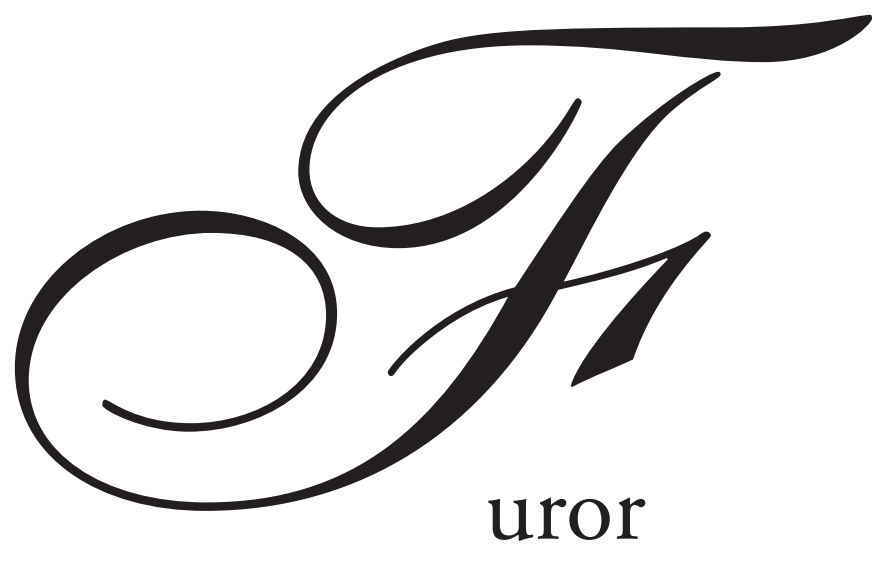

\author{
Ensaios sobre a \\ obra dramática \\ de Hélia Correia
}



Tatjana Manojlovich

Universidade Católica Portuguesa - Lisboa

\section{PERSONAGENS DE ANTÍGONA, HELENA E DE MEDEIA NA TRILOGIA DE HÉLIA CORREIA}

Na mitografia dramática de Hélia Correia, no período dos últimos quinze anos, encontramos três peças alicerçadas em mitos clássicos gregos. Embora estes textos dramáticos tenham como pontos de partida lendas diversas, que pertencem a três ciclos diferentes (o dos Sete Contra Tebas, o da Guerra de Tróia, e o dos Argonautas), podemos considerar que as respectivas recriações, unidas pelo tratamento inovador de temas de protagonistas, bem como pelos seus subtítulos, formam a trilogia.

Duas gregas indomáveis e uma maga bárbara são as figuras centrais de Perdição, de O Rancor e de Desmesura, designados pela Autora como Exercícios sobre Antígona, sobre Helena e com Medeia. Desenharam-se figuras femininas como dominantes e complexas: Antígona, Ama de Antígona, Eurídice e Isménia em Perdição; Helena, Etra e Hermíone em O Rancor; e Medeia, Melana, Éritra e Abar em Desmesura. O forte contraste entre concepções éticas femininas e masculinas confronta os dois mundos inconciliáveis: o fenómeno de heroísmo de guerras e o poder soberano, sobrevalorizados pelo mundo masculino, passam a ser absurdos trágicos, na visão feminina. Antígona, Helena e Medeia transformam ambições pelo poder de Creonte, Menelau e de Jasão, aparentemente inabaláveis, em armadilhas contra eles próprios: as suas aspirações de possuir o poder absoluto ou, no caso de Jasão, a ambição de aproximar-se do trono em Corinto, tornam-se ilusões ou catástrofes. Reminiscências de guerras, o passado violento e a obsessão de vingança alimentam e dominam o presente: 
a Guerra dos Sete Contra Tebas em Perdição, a Guerra de Tróia em O Rancor, e, em Desmesura, os crimes de Medeia na Cólquida e no solo grego.

A originalidade da trilogia consiste em harmonizar nas três peças esquemas míticos diversos: a lenda de Antígona e as Bacantes no Citéron ${ }^{1}$ em Perdição; os mitos de Helena, de Teseu e de Etra, de Ulisses, de Orestes, de Ifigénia, de Andrómaca e de Aquiles em O Rancor; a lenda de Medeia e a história inventada em torno de Abar em Desmesura.

A sensibilidade rara da Autora pela contemplação feminina de motivos de vingança, de guerra e de amor, faz desta tríade uma insigne mitografia.

\section{Antígona}

"Talvez tenha sido o que procuramos no convívio com os clássicos, e Sófocles será o mais clássico dos clássicos, essa posição conquistada por cima das paixões, onde os ventos contrários se vejam claros, palavras vindas de tão longe. ... Antígona, doce, amarga, trágica meditação sobre razão e poder, quase elegia sobre a impossibilidade da lei, lei dos homens e velhas leis, leis do $\operatorname{coração..."~}^{2}$

A peça Perdição - Exercício sobre Antígona ${ }^{3}$, publicada em 1991 e estreada dois anos depois na Comuna, trata o mito tebano de uma das mais nobres e sublimes heroínas da mitologia e arte gregas, fruto do incestuoso casamento do rei de Tebas e da sua mãe, Jocasta. O rol de personagens do seu homólogo clássico, Antígona de Sófocles, é enriquecido com a figura da Ama, e ainda com

\footnotetext{
1 Invocado também no Estásimo III de Rei Édipo, in Sófocles, Rei Édipo, Tradução de Maria do Céu Zambujo Fialho. Lisboa: Edições 70, 1995, p. 128.

2 Jorge Silva Melo, "Tão longe, Sófocles", in Público Livros, 6 de Dezembro 2003, p. 11.

3 Hélia Correia, Perdição - Exercício sobre Antígona. Florbela. Teatro, Lisboa: Dom Quixote, 1991.
} 
dois espectros, o de Antígona e o da Ama. As figuras principais masculinas são Hémon, Creonte e Tirésias, e as secundárias, o Criado e Creonte, o Mensageiro e os Guardas. Em vez do Coro de Anciãos de Tebas, que existe no tragediógrafo, põe-se em palco o Coro de Bacantes.

A peça abre com o Ditirambo das Bacantes, cuja dança selvagem e linguagem lasciva apontam para uma componente nova, erótica, importante no entendimento e na caracterização de Antígona. Um hino a Baco, patrono da cidade, é entoado ao longo da representação. Tirésias, o profeta cego, ocupa o primeiro dos três planos, nos quais corre a acção. Na sua qualidade de narrador, ele interpreta os acontecimentos, sempre afastado do local da acção. A primeira fala do adivinho conduz à abertura do diálogo duplo omnipresente entre Antígona e a Ama, que comanda a acção nos outros dois planos, o dos vivos e o dos mortos. Deste modo, a ambiguidade das figuras da protagonista e da Ama, e a sua discussão constante, permitem que a vida de Antígona flua permanentemente perante nós, no presente e no passado. No regresso a Tebas, em conversa com a Ama, Antígona recorda a sua cadela, que tinha deixado quando partiu com o pai para o exílio. Assim, ela fala, com alguma tristeza, da própria infância. O fantasma de Antígona também recorda:

Ainda me lembro dela. Da minha cadelita. (p. 23)

As mesmas palavras repetem-se no diálogo final no plano dos espectros. Como se o círculo da vida e da morte da jovem princesa se tivesse fechado, deixando intacta, no entanto, a lembrança da sua infância:

Vês? Sou bastante velha para achar que nesse tempo é que fomos felizes. (p.25)

Repare-se que, a partir daí, a sua fala será mais amargurada, determinada pelo longo isolamento e solidão que viveu no exílio: 
Ah, foi o ódio que me alimentou todo este tempo que segui meu pai. Sabes tu a que deusas me votei? Às de vingança, Ama, às de vingança. Foi nos seus bosques que nos abrigámos. (p. 26)

A inovação que Hélia introduz na caracterização de Antígona é o interesse que os homens nela despertam. A heroína lembra-se dos tempos de peregrinação:

Ab, os caminhos, sim. Aquele suor dos bomens. O vinho que escorria pelas barbas doiradas. (p. 27)

No primeiro episódio com Hémon, reparamos numa certa cumplicidade entre os dois jovens, embora Antígona não mostre amor por ele, mas sim a curiosidade pelas suas intenções amorosas, relativamente a ela:

Hém. - Hás-de ser minha esposa. Ou minha concubina. Por lei ou por força. Estou determinado a possuir-te.

Ant. - E não te interessa a minha opinião.

Hém. - Olha a história de deuses. Está cheia destes casos. No entanto, não vês nenhuma queixa sobre as brutalidades do amor.

Ant. - Eras capaz de me obrigar, a mal?

Hém. - Era capaz de tudo para te ter. (p. 31)

Comparando com o passo correspondente ${ }^{4}$ da peça de Anouilh, onde Antígona fala com o seu noivo Hémon (Ant.. - Quando tu pensas que serei tua, não sentes abrir-se-te o peito, numa ânsia de morte?) ${ }^{5}$, a relação entre os dois jovens na peça portuguesa aproxima-se mais da versão francesa do que da

\footnotetext{
4 Jean Anouillh, Antígona, Tradução de Manuel Breda Simões, Lisboa: Editorial Presença, 1965, pp. 48-55.

${ }^{5}$ Ibid., p. 55.
} 
tragédia sofocliana. A jovem heroína de Hélia torna-se provocadora, como se não quisesse deixar Hémon alcançá-la:

Ant. - Amanhã vou ao rio... Estarei muito afastada das mulheres.

Hém. - Onde as águas estreitam. Onde o braço de um homem escondido entre os salgueiros poderia tocar-te.

Ant. -Não. Onde as águas são largas. E fundas. E perigosas.

Hém. - Para eu te salvar?

Ant. - Para me veres morrer e sentires muita pena. (p. 32)

O mesmo olhar aborrecido lança ela sobre a irmã mais nova. A discussão entre as duas irmãs na versão contemporânea revela que Antígona não hesita em mostrar cinismo, relativamente ao comportamento de Isménia:

Volta para os teus bordados, para as tuas amigas. Não me dês em espectáculo a tua pequenez. (p. 51)

O interesse que os homens despertam em Antígona faz parte de uma mais ampla curiosidade, a de conhecer a vida dos adultos. Ela que, desde muito nova, conhece os caminhos cruéis do exílio

Cansei os olhos a guiar o meu pai cego, a tentar ver na noite, como os bichos. (p. 27)

e homens de guerra

Então eu oiço qualquer coisa dentro deles, um tropel de cavalos, um clamor. É o sangue a cantar na lembrança das guerras. (p. 28),

quer descobrir a vida das mulheres adultas: 
Ó minha tia, ensina-me a arte das mulheres... Diz com que enfeites entrançam o cabelo, com que óleo se perfumam. De que modo se deitam, lado a lado com o homem, sobre a pele de carneiro... Diz-me tudo o que pode esperar-se do amor. (pp. 33-34)

Curiosa e, ao mesmo tempo, assustada pelo que viu na noite de Bacanais, Antígona confessa à tia, Eurídice, que sabe do seu segredo de bacante:

Ant. -Eu sei que há outras coisas no mundo das mulheres. Eu vi-te, minha tia.

Euríd. - Tu seguiste-nos?

Ant. - Durante horas, na noite. E depois, de repente, o medo que eu sentia tornou-se insuportável (p. 37) ... Enfeitiçam e assustam quando passam. Destroem tudo, nessas madrugadas. Mordem as crias, as dos animais e as próprias. ... Devoram-nas e riem. São felizes. (p. 39)

Antígona revela que, durante a festa de Bacanais, Dioniso «embebeda os homens com um vinho fortíssimo» (p. 39). Negando a sua experiência de bacante, Eurídice tenta convencê-la de que devia ignorar tudo isso:

És um animalzinho descarado. Por isso Hémon te quer. Gosta das éguas bravas. É o melhor dos nossos domadores. (p. 39)

No plano dos espectros, o tempo não se apresenta como uma componente estável para Antígona. O presente e passado fluem nas suas lembranças, trocadas na ordem cronológica dos acontecimentos. Cabe à Ama corrigir a sua protegida:

Estamos fora do tempo. As sequências dos actos vão perder o sentido. As causas e os motivos tornar-se-ão a teus olhos cada vez mais confusos. (p. 38) 
Toda a estrutura da peça sofocliana se constrói a partir da decisão de Antígona de cumprir a sua obrigação de irmã, e não obedecer ao édito de Creonte. Na versão portuguesa, a estrutura tradicional do mito mantém-se fiel ao modelo antigo, no entanto, concebe-se uma Antígona actual, rebelde e superior aos homens que a rodeiam. No Jornal de Letras, Hélia revela: "Não quis degradar a dimensão heróica de Antígona, mas dei-lhe mais humanidade, até porque a tomei na infância e acompanhei o seu crescimento doloroso, o que implica uma aproximação mais afectiva à personagem.»"

Existe ainda uma significativa característica na composição do drama contemporâneo, que difere do seu padrão clássico. É a sua dupla dimensão de acção, dividida em planos dos vivos e das mortas. Assim, o fulcro da fábula assenta no facto de que tudo o que diz respeito a Antígona já aconteceu. Aquilo que se apresenta como a acção no plano dos vivos não passa a ser a lembrança dos dois fantasmas. Em Sófocles, o ponto de partida da tragédia é a conversa entre as duas irmãs. Em Anouilh, a peça abre com o regresso de Antígona para casa depois de uma longa noite em que deu sepultura ao irmão. Em Hélia, estamos perante um círculo de acontecimentos já vividos, que não se podem mudar. No diálogo final, Antígona pergunta à Ama se ela conseguiria «viver com eles, suportar aquela paz...?» (p. 57), mas a Ama viva não quer dar a resposta. É o espectro dela que descobre a verdade:

Não vês que estás aqui? Que já aconteceu? (p. 57)

A divisão dos discursos paralelos corresponde aos dois planos da composição da peça. As falas dos espectros, breves e sinceras, iluminam a acção e os diálogos dos vivos; tornam-se o espelho que reflecte as palavras hipócritas dos vivos:

\footnotetext{
${ }^{6}$ Hélia Correia, in Jornal de Letras. 21 de Setembro 1993, p. 25.
} 
Ama - E porque havia alguém de a tratar mal? Era a tua cadela. / Ama morta - Matei-a. Bem sabias que eu a tinha matado. (p. 23)

Creonte - No entanto, eu não queria governar. / Ant. morta - ... o meu tio 162 ficou sozinho sobre o trono. Estava cheio de orgulbo... ( pp. 41-42.)

Porém, se lêssemos apenas o diálogo das duas mulheres-fantasma, sem conhecer as falas dos vivos, encarávamos também um discurso circular, cerrado dentro da própria estrutura que, desde que se conheça a fábula mítica, pode existir independentemente do discurso no plano dos vivos. As «lacunas» entre falas das mortas irrompem como sobra do tempo passado, acumulado «agora» no exílio eterno de Antígona, isto é, nas «nossas» recordações:

Afinal acaba bem, visto que é recontado ao longo das idades. Acaba bem, já que faz parte da memória. (p. 23).

Procurando a influência e valores éticos que aproximam as personagens do padrão grego e da peça de Hélia, vemos assim o profundo e isolado sofrimento da Antígona sofocliana numa época bélica, dominada por guerreiros que acabaram de vencer. O percurso dela é incompreendido e solitário, como era o do seu pai. Num outro contexto histórico, todavia, igualmente cruel e obscuro, concebe Anouilh a sua heroína. Ela é apenas uma das protagonistas no teatro onde os papéis já estão determinados. Que materialização de arquétipo clássico encontramos na Antígona portuguesa, no crepúsculo do século XX, cinquenta anos depois de Anouilh ter escrito a sua versão de Antígona? Será que guerras, embora continuem longe de solos pacíficos, nunca mais acabam? Ela também vive numa época violenta, que, mesmo em frágeis períodos de paz, está cheia de reminiscências de guerra:

Então eu oiço qualquer coisa dentro deles, um tropel de cavalos, um clamor. É o sangue a cantar na lembrança das guerras. (p. 28). 
A última frase de Tirésias descreve profundamente os homens guerreiros. A volúpia masculina corresponde a uma outra expressão - saborosa perdição dos sentidos (p.19) das festejadoras de Baco. Esse é o mundo onde Antígona morre: o de ex-combatentes, homens perdidamente obsessivos por temas bélicos e mulheres libidinosas transformadas à noite em bacantes. Sendo assim, a invocação da sua infância apresenta-se como a única pureza que ela jamais viveu. É uma visão pessimista, onde Antígona morta desvaloriza os seus próprios actos enquanto viva:

É preciso dizer-lhe que não avance mais, que não há glória alguma em tudo isso... Tudo aquilo são sonhos que não valem a pena. (p. 57)

É um universo onde criados negam palavras de rainhas:

Criado - Que desgraça, rainha? Não há desgraça aqui. Cada qual segue a sua vocação. (p. 57)

Um mundo onde histórias de Antígona nunca aconteceram (p. 23).

A última palavra da Antígona viva em Perdição é paz.

\section{Helena}

Sobre a multifacetada personagem da rainha de Esparta, Hélia escreveu O Rancor - Exercício sobre Helena ${ }^{7}$, "uma recriação brilhante, polémica e dramaticamente eficiente em torno da figura de Helena» ${ }^{8}$, publicada em 2000.

\footnotetext{
7 Hélia Correia, O Rancor, Lisboa: Relógio D’ Água, 2000.

8 Maria Helena Serôdio, "Balanço literário do ano 2000. A memória no teatro», Vértice 101, JulhoAgosto 2001, p. 82.
} 
Do elenco da peça em três actos, com epílogo, fazem parte: Menelau, Etra, Helena, Hermíone, Pirro, Telémaco, Orestes e as Erínias, deusas do remorso.

Hélia traz ao palco a versão do mito da jovem Helena, ignorado por Homero, que descreve o rapto de Helena por Teseu, na Lacedemónia, antes do casamento com Menelau. Mais tarde, Teseu confiou Helena à mãe, mas Castor e Pólux libertaram a irmã, escravizando Etra. Em O Rancor, as lendas destas duas figuras aliam, cruzando-se com mais um mito feminino, o da irmã de Helena, Clitemnestra. Para Helena, Etra torna-se mais do que uma escrava íntima, que acompanhou Helena para Tróia e no seu regresso com Menelau para Esparta.

O ponto de partida do drama é o episódio da epopeia homérica, que nos fala da visita de Telémaco ao palácio de Menelau em Esparta, descrita no Canto IV da Odisseia. A peça abre com o ensaio do monólogo do famoso Menelau ${ }^{\text {, }}$ enquanto espera Helena e Hermíone para receberem Telémaco, que veio em procura de notícias sobre Ulisses.

A questão fundamental do tema de Helena que se levanta é a mesma que a tradição mítica explora: a culpa de Helena na conquista de Tróia. Hélia recorda-nos os versos da palinódia de Estesícoro dedicados a Helena, que surgem na epígrafe de O Rancor:

Não é verdade esta história.

Não embarcaste nas naus de sólidos bancos.

Não foste à fortaleza de Tróia. ${ }^{10}$

Neste poema lírico, Estesícoro segue um mito tardio, tal como Eurípides no drama Helena, onde a Guerra de Tróia foi gerida por causa de uma mulher

\footnotetext{
9 Descrição de Homero, in Odisseia, Canto IV; Tradução de Frederico Lourenço. Lisboa: Livros Cotovia, 2003, p. 66.

${ }^{10}$ Estesícoro de Hímera (VII-VI a.C.), in Hélade. Antologia da Cultura Grega. Tradução de Maria Helena da Rocha Pereira. Coimbra, 1998.
} 
fantasma, criada de nuvem por Zeus, enquanto a verdadeira, casta Helena foi hospedada na corte do rei egípcio.

Será que em O Rancor a mulher mais bela do mundo antigo está ilibada da culpa ou foi mesmo a sua insigne beleza que motivou a guerra de Gregos e Troianos? Num passo do primeiro acto, Helena, insultada por Pirro diante do marido, ironiza a sua responsabilidade pelo conflito.

Helena (para Telémaco) - Como bem vês, a guerra não foi por minha causa. Meu marido tolera muito bem os insultos que qualquer um me faça...

Parece-te este homem capaz de reunir os exércitos gregos para ir vingar o rapto da mulher? (p. 40)

Superando a mediocridade de Menelau, Helena demonstra o desprezo pela pequenez do marido:

Helena (acariciando-o, com desprezo) - É isso que imaginas, não é, marido meu, sempre que me desejas no teu leito? Que tens uma mulher vencida às tuas ordens? (p. 42)

Enquanto Menelau goza a paz na corte pósbelica espartana, recordando os tempos passados, o seu genro Pirro, um dos guerreiros sobreviventes, não é capaz de parar de matar. A ideia de guerra continua a atrair os homens combatentes em Tróia (Menelau e Pirro), bem como os filhos de heróis mortos, carregados de crimes na família, causados pela mesma guerra (Orestes). Mas o rancor das gregas e troianas, que alimentam "Os sonhos do grande ódio por Helena" (p. 41) vive apenas para a «mulher dos cinco maridos ${ }^{11}$, sem acusarem ambi-

\footnotetext{
11 Teseu, Menelau, Paris, Aquiles e Deifobo são maridos atribuídos a Helena, por alguns mitógrafos. Porém, esta lenda é ignorada em Ilíada.
} 
ções bélicas dos sátrapas gregos e a paixão dos guerreiros pelas armas. Mais uma vez, na cena com Orestes, Helena fala da acusação falsa:

Helena (calmamente) - Sim, como foi possível? Pensa bem. Como podia uma mulher, ainda que bela, ainda mesmo que gerada por um deus, como podia uma mulher causar a guerra mais longa e mais sangrenta que existiu? Como podia uma mulher levar um pai a oferecer a filha em sacrificio só para que os ventos empurrassem os navios com rapidez na direcção de Tróia? (p. 72)

No início do segundo acto, Helena, já humilhada diante de todos com a verdade sobre os seus cabelos, sofre de remorsos, mas pelo prisma da amarga e mordaz Etra, isso é mais um fingimento de Helena. Na relação com Etra, Helena demonstra a maior ambivalência e a complexidade dos sentimentos, que variam da cumplicidade até ao ódio.

O contraste entre a fama da irresistível beleza feminina e a verdadeira aparência de Helena é acentuado pela sua cabeça rapada. A ausência de verdade e as mentiras acumuladas na corte espartana alimentam, gradualmente, a necessidade de descortinar o passado e o presente. Num momento de sinceridade, Etra revela a Helena a história de Ifigénia, a filha ilegítima de Helena com Teseu, confiada, enquanto bebé, a Clitemnestra e Agamemnon.

No terceiro acto, estando todas as figuras presentes, desvendam-se as histórias dos tempos troianos, bem diferentes das suas versões épicas. A verdade emerge naturalmente, sobretudo nas recordações cruzadas de Helena e de Etra. Em última análise, nenhum herói grego saiu inocente de Tróia.

Etra (reflectindo) - Talvez haja momentos em que as coisas se soltam da mentira, como os frutos se desprendem do ramo que os sustinha. Evão rolando até ao sol, no meio da estrada, sob os olhares de todos. E não há nisso acção de deuses nem de humanos, mas tão-só a passagem da própria natureza. E uma vez caído o fruto, nunca mais alguém conseguirá uni-lo à árvore. (p. 80-81). 
No epílogo da peça, o ensaio vai começar de novo. Menelau repete a sua primeira fala. Aparentemente, Helena aceita o papel na festa dedicada ao casamento da filha, Hermíone, com Orestes, e à vinda de Telémaco. Depois de terem contado a versão verídica sobre Tróia, testemunhos sobreviventes (Helena, Etra, Menelau) e os filhos de heróis gregos (Hermione, Telémaco, Orestes) voltam ao universo da Helena mítica, daquela que nunca esteve em Tróia. Contudo, ao entender que Etra a vai abandonar e regressar a Atenas, Helena perde o sorriso.

\section{Helena - Que farei eu sem ela?}

Etra - Reinarás sobre o povo de Esparta. E em certas noites chamarás pelo meu nome, ao perceberes como o ódio das viúvas e órfãs ainda rondam à volta do palácio. (p. 107)

A vingança de Etra acabou-se. A única reminiscência que se conservou de "Tróia (que) não existe» (p. 107) é o rancor das troianas e gregas.

\section{Medeia}

É a Eurípides que Hélia dedica o seu mitodrama mais recente de um tema helénico, a Desmesura - Exercício com Medeia ${ }^{12}$. Feroz e indomável ${ }^{13}$ princesa $^{2}$ mítica de Cólquida, a protagonista da tragédia homónima de Eurípides, Medeia entra no mundo heliano como a personagem central do último Exercício da trilogia.

\footnotetext{
12 A ser publicada por Relógio D’ Água, em Junho de 2006.

13 Descrição horaciana de Medeia, in Horácio, Arte Poética, Tradução de R. M. Rosado Fernandes. Lisboa: Inquérito; 2001, p. 69.
} 
Como na tragédia euripidiana, a acção decorre em Corinto. Das cinco figuras da peça, quatro são femininas, Medeia, Éritra, Melana e Abar, enquanto Jasão surge como a única personagem masculina.

O drama, composto por três partes, abre com Lamento pelos heróis, entoado pelo coro masculino, seguido de Hino a Hécate, cantado pelo coro feminino. A primeira parte da peça começa com o diálogo entre as duas escravas de Medeia, mãe e filha, Melana e Éritra, num dia de chuva. Ao longo da peça é evidente que o exterior escuro e as falas frequentes do mau tempo são significativos na construção do ambiente psicológico das personagens.

\section{Éritra:... Toda a gente em Corinto passa a vida}

A estranhar estas chuvas tão intensas.

Eu própria me recordo de como era

Cheia de sol esta cidade. E quente!

Os Invernos passavam num instante.

Desde que ela chegou, vivemos nisto... ${ }^{14}$

Encontramos neste passo o primeiro dos vários contrastes em quais se baseiam a acção e a relação da protagonista com outras figuras. Medeia é neta do Sol, Hélio, porém todos vêem nela a causa do mau tempo em Corinto. O contraste da chuva omnipresente com o sol desejado alude ao confronto de Medeia com cidadãos. Este motivo conduz a um contraste mais profundo, que se enraíza na identidade étnica das figuras. Melana, Éritra e Jasão são gregos. Medeia é estrangeira. Fazem parte deste contraste as aparências das figuras femininas. O que é grego, é belo: Jasão fala da beleza de Melana enquanto jovem, e dos cabelos ruivos de Éritra, "O único sol que aqui há dentro», sem

\footnotetext{
14 Este artigo foi entregue antes da Desmesura - Exercícios com Medeia ser publicada. Por este motivo, os passos citados não possuem as referências de páginas.
} 
mencionar a beleza de Medeia. Embora bela, Medeia tem cabelos negros, tal como a sua escrava Abar, pois negra é a cor da barbárie.

O terceiro contraste reside no facto de Medeia pertencer a uma famosa família maga. A sua tia é a feiticeira Circe, filha do Sol, que purificou Medeia e Jasão do assassínio de Absirto, no regresso de Cólquida. Sendo sacerdotisa de Hécate, deusa de magos e feiticeiras, Medeia é perita em artes ocultas. Os actos de Medeia na Cólquida, na época do rapto do velo de ouro, e mais tarde em Iolcos, ainda vivem na memória de cidadãos de Corinto. Logo no discurso inicial, bem como em certos passos ao longo da peça, implica-se a presença do medo da natureza de Medeia e dos seus poderes.

\section{Éritra: - Ela consegue ouvir-nos a pensar...}

Significativo é o tratamento dado à entrada de Medeia na cena. Ela surge com Abar, falando em colco, e exigindo que a núbia continuasse a falar essa língua. Assim, é evidente que Medeia seja estrangeira na casa em que se supõe ser senhora, onde a mãe e a filha escravizadas estão mais à vontade do que ela. O vulto de Abar, de sangue egípcio-negro, é selvagem, visto da perspectiva grega. A núbia, ensinada por Medeia a falar em colco, torna-se a personificação da bárbara e incompreensível língua da princesa de Cólquida ${ }^{15}$. A extrema fragilidade física da escrava mais íntima de Medeia, o seu «único consolo aqui» ${ }^{16}$, simboliza o fim do convívio harmonioso de Medeia com Jasão no exílio. É verdade que a casa na polis não tem qualquer importância para Medeia. Uma vez afastada da Cólquida, os seus actos nas cidades de Iolcos e de Corinto aprofundaram o seu estatuto de estrangeira. Sem falar em grego da nostalgia que sente, ela só abre o coração, na tentativa de salvar a vida de Abar, falando em colco:

\footnotetext{
$\overline{15}$ Cólquida é o nome grego para a Geórgia oeste.

16 Palavras de Medeia num dos primeiros passos no diáogo com Abar, depois de ambas terem entrado em cena.
} 
Medeia: - .. Ó cidade de Aea, ó minha Cólquida das montanhas azuis,

Phásis, amado rio, salvai esta mulher.

Porque ela é tudo o que tenho de vós.

Falar com ela na minha língua é tudo que me resta.

A lingua e o amor são os dois bens preciosos para a antiga princesa da Cólquida. O seu passado é sobrecarregado de traição à pátria, à família e do fratricídio, o que faz de Medeia uma eterna refugiada. A tradição mítica fala-nos do casamento arranjado de Jasão e Creúsa ${ }^{17}$, filha do rei de Corinto, enquanto Jasão ainda era casado com Medeia. Enquanto na tragédia euripidiana Medeia já sabe da traição do marido, Hélia dá ao tema um novo caminho, no qual a protagonista gradualmente reconhece os sinais do comportamento mudado de Jasão.

Ao longo da primeira parte do drama, Medeia permanece humana, na luta por salvar o amor do marido afastado. O seu comportamento não implica os traços da feiticeira magoada. Simultaneamente, Jasão é caracterizado pela ambição de se aproximar do trono local, bem como pela paixão por Éritra, filha ilegítima do rei de Corinto e irmã da princesa Glauce. O perfil de Jasão é dado, numa forma irónica, no discurso de Jasão com Melana e Éritra, na segunda parte da peça:

Jasão: - Tanto medo tens dela?

Melana: - Sim, confesso. Assim tu confessasses.

Jasão: - Quê?

Melana: - Que a temes...

Jasão: - Temer minha mulher? Estás doida?

Éritra: - Ó, mãe!

Esqueceste por acaso essa prudência

$\overline{17}$ Chamada também Glauce. Eurípides não nomeia a princesa de Corinto. 
De que tanto te fartas de falar?

Insultas o nosso amo, o herói da Grécia?

Jasão: - Por amor desta bela rapariga

Perdoo essas palavras....

O célebre líder dos Argonautas é incapaz de falar sobre o divórcio a sós com Medeia, e pede a Melana que assista, prometendo-lhe a liberdade. O discurso que se segue depois do aparecimento de Medeia, envolvendo todas as figuras, é um dos mais fortes segmentos do drama, onde Hélia retrata uma Medeia quase ingénua se comparada com as outras personagens. A tensão do conflito de Medeia e Jasão cresce progressivamente, provocando uma certa compaixão em relação a Medeia. Apesar de ser maga, marcada pelos outros de saber adivinhar e ler os pensamentos, ela fica paralisada ao ouvir o marido falar da sua intenção de casar com Glauce. A partir desse passo, Medeia muda o comportamento. Em vez de sofrer, sendo humilhada por Jasão diante das criadas, Medeia concebe a vingança e finalmente age.

Medeia: -... O meu mundo acabou. Começou outro.

No fim da segunda parte, Hélia dá-nos um dos mais belos monólogos de Medeia e da trilogia, falando do amor que sente por Jasão:

É com ele que eu respiro e me alimento.

Não com o ar, não com os frutos, não.

Tudo na minha vida é trajectória

Que converge para ele como uma seta

Corre o meu sangue para o seu sangue,

O riso para dentro do seu riso. E aos meus filhos,

Se tanto os amo, é porque vejo neles

O rosto do seu pai... 
Nesta fala de Medeia, a sensibilidade do lado humano dela supera a crueldade dos seus crimes do passado, feitos no papel de maga, na época da recuperação do velo de ouro pelos Argonautas. Simultaneamente, Medeia despreza as paixões fracas dos mortais, chamando às bacantes "cordeiros» comparando com ela. Assim, ultrapassa não apenas a sua posição de estrangeira no solo grego, mas também a metade humana do seu ser semidivino.

A fala de Abar, na bela manhã de sol, abre a terceira parte da peça. O Sol, o fogo e a Morte, as componentes do mundo mago de Medeia, são simbolizados por Hélio, Circe e Hécate. Evocando a deusa ctónica, Medeia assassina Glauce com fogo; contudo, ainda não desiste de Jasão. Tenta convencer o marido a voltar para a Cólquida, para o seu "doce país dos montes e dos nevoeiros», mas vê a proposta recusada por ele. No último diálogo com Jasão, Medeia compreende que o marido a vai abandonar e, finalmente, centra a sua vingança em Jasão. O amor e a língua apagam-se com os filhos e Abar. Medeia aniquila o seu passado humano, as suas maternidade e lealdade à família.

Depois de ter assassinado a núbia e as crianças, ela declara ferozmente a sua vontade:

Medeia: - ... Cidadãos gregos, tudo o que vos cabe

É somente ir contando a minha história

Até que um de entre vós a compreenda!

Assim termina uma das mais belas peças de Hélia, dedicada a um cidadão grego que, na forma de tragédia, contemplou e compreendeu profundamente o amor desmesurado de Medeia. 



\section{Série}

\section{Documentos}

Imprensa da Universidade de Coimbra

Coimbra University Press

2006

- $\mathrm{U}$

C • 